\title{
A winking anus may signify spinal injury
}

Case report - A 41 year old woman was referred for assessment of worsening bladder and bowel dysfunction. At the age of 17 years she had suffered a traumatic fracturesubluxation of T12-L1 following a trampoline accident in which she fell heavily on to her back. She immediately lost sensation below the waist but this returned over several days. Following eight weeks of bed rest she gradually regained the ability to walk. She subsequently had no neurological deficit in her legs.

Since the accident she had experienced bladder and bowel dysfunction. She experienced urinary frequency, urgency, urge incontinence, and episodes of spontaneous bladder emptying without warning. There had been no stress incontinence. Urodynamic studies showed a small capacity bladder of $257 \mathrm{ml}$ but good voiding and minimal residual volume $(30 \mathrm{ml})$. She did however have marked urgency at $150 \mathrm{ml}$.

From a gastrointestinal point of view, she developed constipation following her injury. During her twenties she passed several small firm stools daily. During her thirties she developed episodes of abdominal pain, occurring approximately every two months, followed by diarrhoeal episodes over several hours. Continence was not impaired. Colonoscopy was normal.

On rectal examination the anus was closed at rest and of reasonable tone initially but gaped after digital examination (figs 1,2) for several minutes, with eventual return to normal resting tone. Palpable voluntary anal sphincter contraction was absent. Perianal skin sensation to light touch and pinprick was reduced.

Anorectal physiological testing showed a low maximum resting anal pressure $\left(45 \mathrm{~cm} \mathrm{H}_{2} \mathrm{O}\right.$, normal >60), indicating internal anal sphincter dysfunction, and a low maximum anal squeeze pressure $\left(8 \mathrm{~cm} \mathrm{H}_{2} \mathrm{O}\right.$, normal $\left.>60\right)$, indicating external sphincter dysfunction. The sensory threshold to an electrical stimulus was grossly abnormal in both the rectum $(61 \mathrm{~mA}$, normal <35) and the anal canal $(88 \mathrm{~mA}$, normal <12).

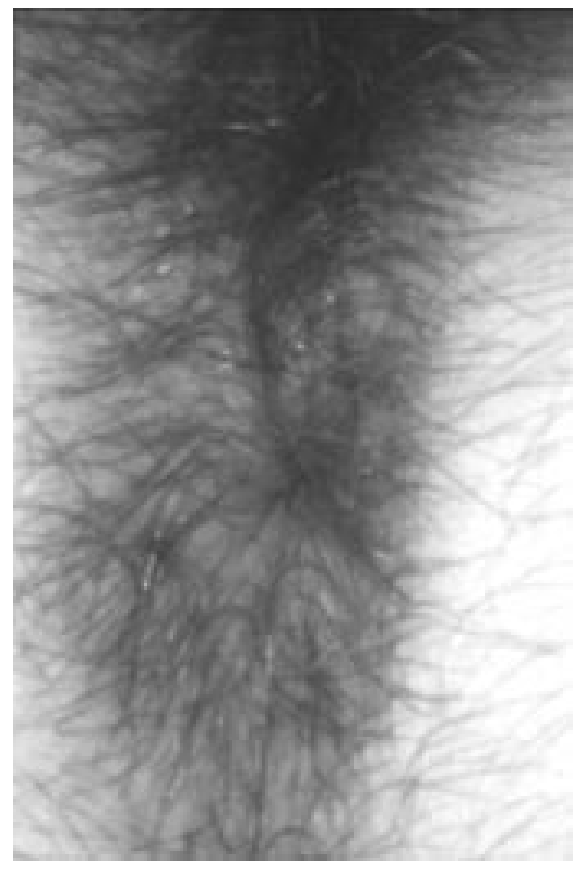

Figure 1 Anus closed at rest.
Management consisted of simple symptomatic measures, including analgesics and antidiarrhoeal medica-

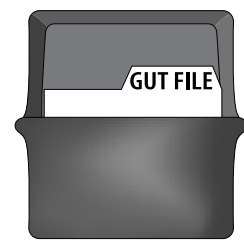
tions as required.

Discussion-Bowel dysfunction is common in the general population but is especially common after spinal injury. A study of 115 chronically spinally injured patients showed that $95 \%$ experienced constipation, faecal incontinence, or both. ${ }^{1}$ Fifty per cent of patients relied on the help of another person for bowel evacuation. Patients rated their bowel disability almost as troublesome as their loss of physical mobility, and worse than their urinary symptoms. Although these data refer to patients with permanent paraor quadriplegia, bowel dysfunction can also persist after partial or transient spinal lesions.

As bowel dysfunction is also common in the general population, especially in young women, it is helpful to have a test that distinguishes idiopathic functional disturbance from that related to permanently impaired neurological innervation. This is important for clinical reasons, as the former may respond more easily to behavioural techniques such as biofeedback retraining. ${ }^{2}$ It is also of medicolegal importance. The testing of rectal sensation to an electrical stimulus ${ }^{3}$ often enables this distinction to be made, providing clear evidence in our patient of impaired innervation.

To our knowledge the sign of anal gaping after digital examination as a marker of neurological impairment has not been described previously. Normally the anal canal remains closed before, during, and after examination. The decrease in anal tone after digital examination in this patient may reflect loss of the normal extrinsic parasympathetic excitatory drive to the internal anal sphincter smooth muscle which maintains tone, and unopposed extrinsic sympathetic drive which relaxes the sphincter. ${ }^{4}$ Given that this was a T12-L1 lesion, only part of the sympathetic outflow may have been lost. It is uncertain what proportion of parasympathetic and sympathetic

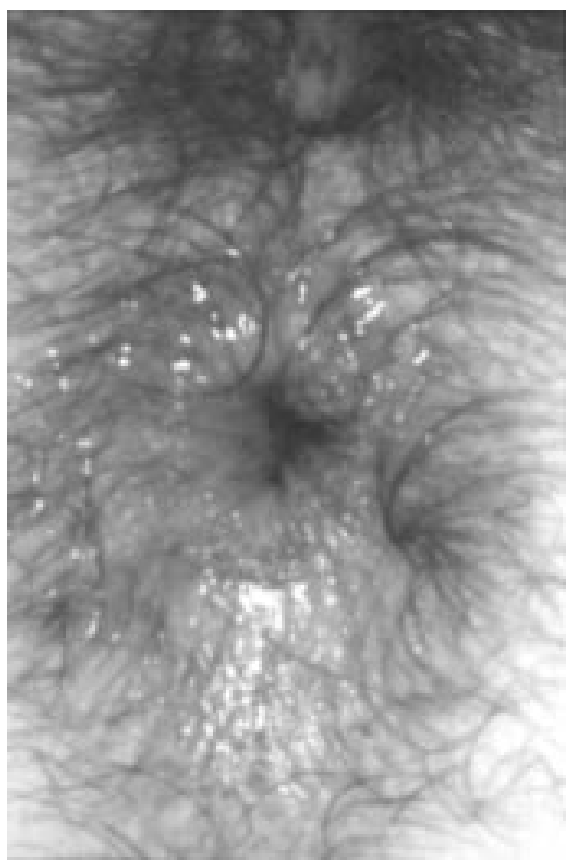

Figure 2 Gaping anus two minutes after digital examination. 
autonomic innervation remained. Lack of modulation of sacral reflexes involving the sphincter and sacral spinal cord from cerebral centres may also contribute to this abnormality. The abnormal rectal sensation and bladder dysfunction provided supportive evidence that the "winking anus sign" is truly a reflection of impaired innervation. This patient was probably not incontinent because of her firm stools.

This sign should be distinguished from the "gaping anus" seen in some patients with faecal incontinence or rectal prolapse. In these patients anal tone is permanently diminished and the sphincter remains "open".

Some patients develop worsening bowel symptoms many years after their spinal injury. This may relate to progressive enteric neurological changes secondary to chronic loss of extrinsic innervation, although evidence in support of this has not been sought.

$$
\begin{array}{r}
\text { A J MALOUF } \\
\text { M A KAMM } \\
\text { St Mark's Hospital, London, UK }
\end{array}
$$

Correspondence to:Professor M A Kamm, St Mark's Hospital, Watford Road, Harrow, Middlesex HA1 3UJ, UK

1 Glickman S, Kamm MA. Bowel dysfunction in spinal cord injury patients. Lancet 1996;347:1651-3.

2 Chiotakakou-Faliakou E, Kamm MA, Roy AJ, et al. Biofeedback provides long term benefit for patients with intractable slow and normal transit constipation. Gut 1998;42:517-21.

3 Kamm MA, Lennard-Jones JE. Rectal mucosal electrosensory testing. Evidence for a sensory neuropathy in severe constipation. Dis Colon Rectum 1990;33:419-23.

4 Speakman CTM, Hoyle CHV, Kamm MA, et al. The adrenergic control of the internal anal sphincter is abnormal in patients with idiopathic faecal incontinence. Br F Surg 1990;77:1342-4.

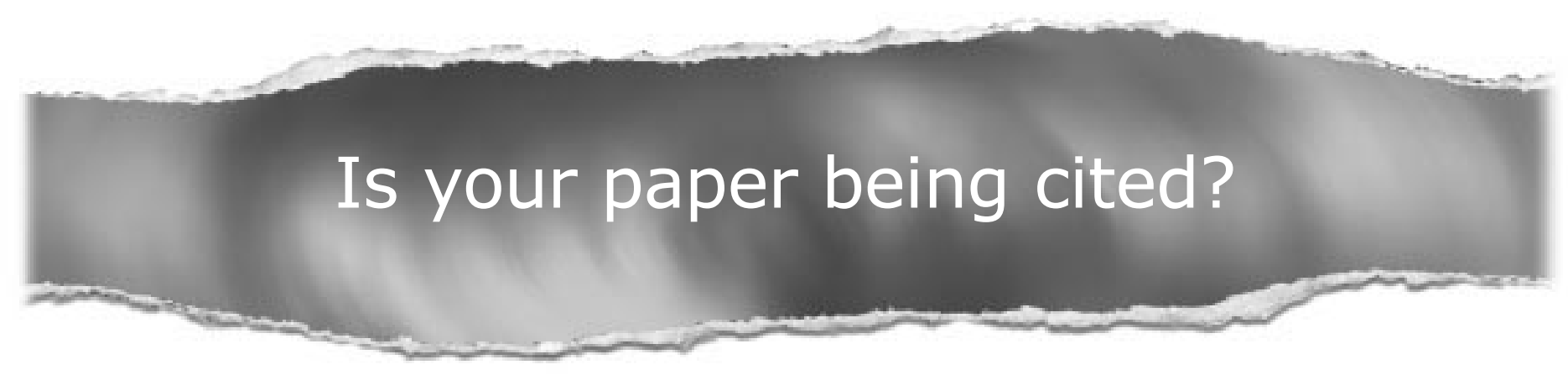

\section{CiteTrack service}

CiteTrack will alert you by email whenever new content in Gut or a participating journal is published that matches criteria you want to track

Topics: Tell CiteTrack which words or subjects to watch for in new content Authors: Be alerted whenever key authors you are following publish a new paper Articles: Know whenever a paper of interest to you is referenced by another paper

\section{www.gutjnl.com}

